\title{
Milheto em dietas de suínos em crescimento e terminação
}

\author{
Millet in diets of growing and finishing pigs
}

\author{
Rodrigo Caetano de Abreu ${ }^{\mathrm{I}}$ Charles Kiefer ${ }^{\mathrm{II}}$ Fabiana Villa Alves ${ }^{\mathrm{III}}$ Danilo Alves Marçal \\ Bruna Ferreira de Oliveira ${ }^{\mathrm{I}}$ Leandro Pereira Martins ${ }^{\mathrm{IV}}$ Elaine Marisa Rosa $^{\mathrm{IV}}$
}

RESUMO

Realizou-se este estudo com o objetivo de avaliar níveis de milheto híbrido $A D R 8010^{\circledR}$ nas dietas de suínos em crescimento e terminação sobre o desempenho e características quantitativas de carcaça. Foram utilizados 48 animais, machos castrados, geneticamente similares, com peso inicial de $30,0 \pm 2,9 \mathrm{~kg}$. Os animais foram distribuídos em delineamento experimental de blocos casualizados, com quatro níveis de inclusão de milheto na dieta $(0 ; 25 ; 50 ;$ e 75\%), seis repetições, sendo cada unidade experimental constituída por dois animais. Foram analisados os parâmetros de desempenho (consumo de ração, ganho de peso e conversão alimentar) e as características de carcaça (peso e comprimento de carcaça, espessura de toucinho, profundidade de músculo, percentual e quantidade de carne magra). Os níveis de milheto não influenciaram $(P>0,05)$ nos parâmetros de desempenho e características de carcaça dos suínos. O milheto ADR $8010^{\circledR}$ pode substituir o milho em até $75 \%$ nas dietas de suínos em crescimento e terminação, sem prejudicar o desempenho e características de carcaça dos animais.

Palavras-chave: alimento energético, carcaça, desempenho, híbrido ADR $8010^{\circledR}$.

\section{ABSTRACT}

The aim of this study was to evaluate levels of millet hybrid $A D R 8010^{\circledR}$ in the diets of pigs in growing and finishing on performance and carcass quantitative characteristics. It was used 48 barrows, genetically similar $c$, with initial weight around $30.0 \pm 2.9 \mathrm{~kg}$. The animals were distributed in a randomized block design, with four levels of inclusion of millet in the diet $(0 ; 25$; 50 and 75\%), six replicate of two animals each. It was analyzed the parameters of performance (feed intake, weight gain and feed conversion) and carcass traits (weight and height of carcass, back fat thickness, depth of muscle, percentage and amount of lean meat). The level of inclusion of millet do not influence $(P>0.05)$ the parameters of performance and characteristics of carcass of pigs. The millet ADRR $8010^{\circledR}$ can replace the corn up to $75 \%$ on diets of pigs in growth and finishing without impacting performance and carcass characteristics of animals.

Key words: carcass, energetic food, hybrid ADR $8010^{\circledR}$, performance.

\section{INTRODUÇÃO}

Diversas pesquisas têm demonstrado que o milho pode ser substituído parcial ou totalmente por alimentos alternativos nas dietas de suínos em crescimento e terminação (BASTOS et al., 2002; BASTOS et al., 2004; KIEFER \& QUADROS, 2006; MARQUES et al., 2007). Dentre os substitutos do milho, está o milheto, gramínea anual com grande potencial de cultivo como cultura de entressafra (safrinha). O milheto também pode ser uma alternativa de cultivo quando os padrões de temperatura e chuvas estiverem abaixo do necessário para o plantio do milho, de tal forma que os rendimentos seriam negativamente afetados pela seca de verão ou por uma estação de crescimento curta (SALTON et al., 1995).

Dentre as vantagens do milheto, em relação ao milho, estão o maior teor proteico e maior digestibilidade dos aminoácidos (ROSTAGNO et al., 2011), além de ausência de tanino e micotoxinas (RAGHAVENDER \& REDDY, 2009), sendo que a única desvantagem do milheto está relacionada ao seu

\footnotetext{
IPrograma de Pós-graduação em Ciência Animal, Universidade Federal de Mato Grosso do Sul (UFMS), Campo Grande, MS, Brasil.

"UFMS, 97070-900, Campo Grande, MS, Brasil. E-mail: charles.kiefer@ufms.br. Autor para correspondência.

IIIEmbrapa Gado de Corte, Campo Grande, MS, Brasil.

IvAcadêmicos do curso de Zootecnia, UFMS, Campo Grande, MS, Brasil. 
reduzido valor energético (LAWRENCE et al., 1995). Além disso, em situações de preços elevados do milho, o milheto pode contribuir para redução dos custos das dietas e melhorar a viabilidade econômica da produção animal (MURAKAMI et al., 2009). Nesse sentido, realizou-se este estudo com o objetivo de avaliar níveis de milheto híbrido ADR $8010^{\circledR}$ nas dietas de suínos em crescimento e terminação sobre o desempenho e características quantitativas de carcaça.

\section{MATERIAL E MÉTODOS}

Foram utilizados 48 animais, machos castrados, geneticamente similares, com peso inicial de $30,0 \pm 2,9 \mathrm{~kg}$. Os animais foram distribuídos em delineamento experimental de blocos casualizados, com quatro níveis de inclusão do milheto $(0,25$, 50 e 75\%), seis repetições, sendo cada unidade experimental constituída por dois animais.O milheto utilizado para a elaboração das dietas experimentais foi o híbrido ADR $8010^{\circledR}$. A determinação da composição nutricional para proteína e aminoácidos totais do milheto foi realizada pelo método analítico, no laboratório da Evonik Animal Nutrition Services (Tabela 1). A partir dos valores totais analisados e dos coeficientes de digestibilidade descritos por ROSTAGNO et al. (2011), foram estimados os níveis de aminoácidos digestíveis do milheto.

As dietas experimentais foram isonutritivas, formuladas de modo a atender as exigências nutricionais estabelecidas por ROSTAGNO et al. (2011), para suínos machos castrados, de alto

Tabela 1 - Composição nutricional analisada do milheto híbrido $8010^{\circledR}$.

\begin{tabular}{lccc}
\hline Nutriente & Total (\%) & $\begin{array}{c}\text { Coeficiente de } \\
\text { digestibilidade } \\
(\%)^{2}\end{array}$ & $\begin{array}{c}\text { Aminoácido } \\
\text { digestível } \\
(\%)\end{array}$ \\
\hline $\begin{array}{l}\text { Proteína bruta } \\
\text { Lisina }\end{array}$ & 11,9 & - & - \\
Treonina & 0,35 & 81,9 & 0,29 \\
Metionina + & 0,46 & 80,3 & 0,37 \\
Cistina & 0,50 & 91,3 & 0,46 \\
Valina & 0,63 & 88,0 & 0,55 \\
Arginina & 0,53 & 94,8 & 0,50 \\
Histidina & 0,28 & 94,6 & 0,26 \\
Triptofano & 0,13 & 85,7 & 0,11 \\
Leucina & 1,20 & 89,8 & 1,08 \\
Isoleucina & 0,49 & 87,3 & 0,43 \\
Fenilalanina & 0,60 & 90,0 & 0,54 \\
\hline
\end{tabular}

${ }^{1}$ Laboratório Evonik Animal Nutrition Services; ${ }^{2}$ ROSTAGNO et al. (2011). potencial genético e desempenho superior dos 30 aos $50 \mathrm{~kg}$ (Tabela 2), dos 50 aos $70 \mathrm{~kg}$ (Tabela 3) e dos 70 aos $100 \mathrm{~kg}$ (Tabela 4). A ração foi fornecida ad libitum aos animais durante todo o período experimental.

Durante o período experimental, a temperatura e a umidade relativa do ambiente foram monitoradas diariamente às 8 e 16 horas, por meio de um conjunto de termômetros de máxima e mínima, de bulbo seco e bulbo úmido e de globo negro. Os valores registrados foram convertidos no índice de temperatura de globo e umidade (ITGU), segundo BUFFINGTON et al. (1981), caracterizando o ambiente térmico em que os animais foram mantidos.

Tabela 2 - Composição centesimal e nutricional das dietas experimentais para suínos em fase de crescimento (30-50kg).

\begin{tabular}{|c|c|c|c|c|}
\hline \multirow{2}{*}{ Ingredientes (\%) } & \multicolumn{4}{|c|}{------- Níveis de milheto, \% ----- } \\
\hline & 0 & 25 & 50 & 75 \\
\hline Milho & 75,47 & 53,61 & 29,63 & 5,64 \\
\hline Milheto & 0,00 & 25,00 & 50,00 & 75,00 \\
\hline Farelo de soja, $45 \%$ & 20,04 & 16,83 & 14,00 & 11,17 \\
\hline Óleo de soja & 0,00 & 1,19 & 2,79 & 4,52 \\
\hline Caulim & 1,12 & 0,00 & 0,00 & 0,00 \\
\hline Fosfato bicálcico & 1,18 & 1,19 & 1,22 & 1,24 \\
\hline Calcário calcítico & 0,72 & 0,73 & 0,73 & 0,73 \\
\hline Mistura mineral $^{1}$ & 0,10 & 0,10 & 0,10 & 0,10 \\
\hline Mistura vitamínica ${ }^{2}$ & 0,40 & 0,40 & 0,40 & 0,40 \\
\hline Sal comum & 0,41 & 0,41 & 0,42 & 0,43 \\
\hline L-Lisina $\mathrm{HCl}$ & 0,37 & 0,44 & 0,50 & 0,56 \\
\hline DL-Metionina & 0,09 & 0,09 & 0,08 & 0,07 \\
\hline L-Treonina & 0,11 & 0,12 & 0,14 & 0,15 \\
\hline L-Triptofano & 0,01 & 0,01 & 0,01 & 0,01 \\
\hline Bacitracina de Zinco & 0,04 & 0,04 & 0,04 & 0,04 \\
\hline \multicolumn{5}{|l|}{$\begin{array}{l}\text { Composição nutricional } \\
\text { calculada }\end{array}$} \\
\hline Proteína bruta (\%) & 15,81 & 15,60 & 15,30 & 15,14 \\
\hline EL (kcal/kg) & 2.400 & 2.400 & 2.400 & 2.400 \\
\hline Lisina digestível, (\%) & 0,943 & 0,943 & 0,943 & 0,943 \\
\hline Met+Cist digestível, (\%) & 0,556 & 0,556 & 0,556 & 0,556 \\
\hline Treonina digestível, (\%) & 0,613 & 0,613 & 0,613 & 0,613 \\
\hline Triptofano digestível, (\%) & 0,170 & 0,170 & 0,170 & 0,170 \\
\hline Valina digestível, (\%) & 0,651 & 0,651 & 0,651 & 0,651 \\
\hline Cálcio (\%) & 0,635 & 0,635 & 0,635 & 0,635 \\
\hline Fósforo disponível, (\%) & 0,314 & 0,314 & 0,314 & 0,314 \\
\hline Sódio (\%) & 0,180 & 0,180 & 0,180 & 0,180 \\
\hline
\end{tabular}

${ }^{1}$ Conteúdo por quilograma de ração: cobre-0,03g; ferro-0,1g; iodo-1,9mg; manganês-0,07g; zinco-0,16g.

${ }^{2}$ Conteúdo por quilograma de ração: colina-0,4872g; niacina30mg; vit. B12-25mcg; vit.B2-5mg; vit.k3- 5mg; selênio-0,3mg; vit.B6-3mg; ácido fólico-1,5mg; vit.A-10.000UI; vit.D3-2000UI; ácido pantotênico-10,816mg; vit.B1-2mg, biotina-0,3mg, vit.E50UI. 
Tabela 3 - Composição centesimal e nutricional das dietas experimentais para suínos em fase de crescimento (50-70kg).

\begin{tabular}{|c|c|c|c|c|}
\hline \multirow{2}{*}{ Ingredientes (\%) } & \multicolumn{4}{|c|}{------- Níveis de milheto, \% ------ } \\
\hline & 0 & 25 & 50 & 75 \\
\hline Milho & 77,35 & 57,21 & 33,21 & 9,21 \\
\hline Milheto & 0,00 & 25,00 & 50,00 & 75,00 \\
\hline Farelo de soja, $45 \%$ & 17,58 & 14,04 & 11,21 & 8,39 \\
\hline Óleo de soja & 0,00 & 0,52 & 2,25 & 3,98 \\
\hline Caulim & 1,95 & 0,00 & 0,00 & 0,00 \\
\hline Fosfato bicálcico & 0,95 & 0,96 & 0,99 & 1,01 \\
\hline Calcário calcítico & 0,66 & 0,67 & 0,67 & 0,68 \\
\hline Mistura mineral $^{1}$ & 0,10 & 0,10 & 0,10 & 0,10 \\
\hline Mistura vitamínica $^{2}$ & 0,40 & 0,40 & 0,40 & 0,40 \\
\hline Sal comum & 0,38 & 0,39 & 0,39 & 0,40 \\
\hline L-Lisina $\mathrm{HCl}$ & 0,38 & 0,46 & 0,52 & 0,57 \\
\hline DL-Metionina & 0,09 & 0,07 & 0,07 & 0,06 \\
\hline L-Treonina & 0,11 & 0,12 & 0,14 & 0,15 \\
\hline L-Triptofano & 0,02 & 0,02 & 0,01 & 0,01 \\
\hline Bacitracina de Zinco & 0,04 & 0,04 & 0,04 & 0,04 \\
\hline \multicolumn{5}{|l|}{$\begin{array}{l}\text { Composição nutricional } \\
\text { calculada }\end{array}$} \\
\hline Proteína bruta (\%) & 14,86 & 14,65 & 14,42 & 14,20 \\
\hline EL (kcal/kg) & 2.400 & 2.400 & 2.400 & 2.400 \\
\hline Lisina digestível, (\%) & 0,891 & 0,891 & 0,891 & 0,891 \\
\hline Met+Cist digestível, (\%) & 0,526 & 0,526 & 0,526 & 0,526 \\
\hline Treonina digestível, (\%) & 0,579 & 0,579 & 0,579 & 0,579 \\
\hline Triptofano digestível, (\%) & 0,160 & 0,160 & 0,160 & 0,160 \\
\hline Valina digestível, (\%) & 0,610 & 0,610 & 0,610 & 0,610 \\
\hline Cálcio (\%) & 0,552 & 0,552 & 0,552 & 0,552 \\
\hline Fósforo disponível, (\%) & 0,269 & 0,269 & 0,269 & 0,269 \\
\hline Sódio (\%) & 0,170 & 0,170 & 0,170 & 0,170 \\
\hline
\end{tabular}

${ }^{1}$ Conteúdo por quilograma de ração: cobre -0,03g; ferro - 0,1g; iodo -1,9mg; manganês - 0,07g; zinco - 0,16g.

${ }^{2}$ Conteúdo por quilograma de ração: colina - 0,4872g; niacina 30mg; vit. B12 - 25mcg; vit. B2 - 5mg; vit. K 3 - 5mg; selênio 0,3mg; vit. B6 - 3mg; ácido fólico - 1,5mg; vit. A - 10.000UI; vit. D3 - 2000UI; ácido pantotênico - 10,816mg; vit. B1 - 2mg, biotina - 0,3mg, vit. E - 50UI.

Foram coletados diariamente os resíduos de ração do chão e somados às sobras do comedouro ao final do período experimental, para determinar o consumo de ração diário. Foram realizadas quatro pesagens por ocasião do início de cada fase e ao final do experimento para obtenção de dados relativos ao ganho de peso e à conversão alimentar. Ao término do experimento, os animais foram pesados e, após a pesagem, permaneceram em jejum de sólidos por 8 horas para serem transportados ao frigorífico.

Ao chegarem ao frigorífico, foram pesados para determinar o peso vivo de frigorífico e o rendimento de carcaça. Após um período de descanso
Tabela 4 - Composição centesimal e nutricional das dietas experimentais para suínos em fase de terminação (70-100kg).

\begin{tabular}{|c|c|c|c|c|}
\hline \multirow{2}{*}{ Ingredientes (\%) } & \multicolumn{4}{|c|}{------- Níveis de milheto, \% ------ } \\
\hline & 0 & 25 & 50 & 75 \\
\hline Milho & 77,84 & 57,91 & 33,18 & 8,46 \\
\hline Milheto & 0,00 & 25,00 & 50,00 & 75,00 \\
\hline Farelo de soja, $45 \%$ & 16,88 & 13,85 & 11,72 & 9,59 \\
\hline Óleo de soja & 0,00 & 0,33 & 2,12 & 3,92 \\
\hline Caulim & 2,42 & 0,00 & 0,00 & 0,00 \\
\hline Fosfato bicálcico & 0,85 & 0,86 & 0,88 & 0,90 \\
\hline Calcário calcítico & 0,62 & 0,63 & 0,64 & 0,64 \\
\hline Mistura mineral $^{1}$ & 0,10 & 0,10 & 0,10 & 0,10 \\
\hline Mistura vitamínica $^{2}$ & 0,40 & 0,40 & 0,40 & 0,40 \\
\hline Sal comum & 0,36 & 0,36 & 0,37 & 0,38 \\
\hline L-Lisina $\mathrm{HCl}$ & 0,32 & 0,38 & 0,42 & 0,46 \\
\hline DL-Metionina & 0,06 & 0,04 & 0,03 & 0,02 \\
\hline L-Treonina & 0,09 & 0,10 & 0,11 & 0,11 \\
\hline L-Triptofano & 0,01 & 0,00 & 0,00 & 0,00 \\
\hline Bacitracina de Zinco & 0,04 & 0,04 & 0,04 & 0,04 \\
\hline \multicolumn{5}{|l|}{$\begin{array}{l}\text { Composição nutricional } \\
\text { calculada }\end{array}$} \\
\hline Proteína bruta (\%) ${ }^{3}$ & 14,50 & 14,50 & 14,50 & 14,50 \\
\hline EL (kcal/kg) & 2.400 & 2.400 & 2.400 & 2.400 \\
\hline Lisina digestível, (\%) & 0,829 & 0,829 & 0,829 & 0,829 \\
\hline Met+Cist digestível, (\%) & 0,497 & 0,497 & 0,497 & 0,497 \\
\hline Treonina digestível, (\%) & 0.555 & 0,555 & 0.556 & 0,555 \\
\hline Triptofano digestível, (\%) & 0,149 & 0,149 & 0,150 & 0,155 \\
\hline Valina digestível, (\%) & 0,598 & 0,598 & 0,598 & 0,598 \\
\hline Cálcio (\%) & 0,512 & 0,512 & 0,512 & 0,512 \\
\hline Fósforo disponível, (\%) & 0,250 & 0,250 & 0,250 & 0,250 \\
\hline Sódio (\%) & 0,160 & 0,160 & 0,160 & 0,160 \\
\hline
\end{tabular}

${ }^{1}$ Conteúdo por quilograma de ração: cobre - 0,03g; ferro - 0,1g; iodo - 1,9mg; manganês - 0,07g; zinco - 0,16g.

${ }^{2}$ Conteúdo por quilograma de ração: colina - 0,4872g; niacina 30mg; vit. B12 - 25mcg; vit. B2 - 5mg; vit. K3 - 5mg; selênio 0,3mg; vit. B6 - 3mg; ácido fólico - 1,5mg; vit. A - 10.000UI; vit. D3 - 2000UI; ácido pantotênico - 10,816mg; vit. B1 - 2mg, biotina - 0,3mg, vit. E - 50UI.

de 12 horas, os animais foram insensibilizados por eletronarcose, sacrificados pela secção dos grandes vasos do pescoço, escaldados e eviscerados.

Ao final da linha de abate, as carcaças foram pesadas e divididas em duas por um corte longitudinal na linha dorso-lombar, que corresponde à coluna vertebral. Foram mensurados os comprimentos de carcaça, medindo-se da borda cranial da primeira costela até a borda cranial da sínfise pubiana, com auxílio de fita métrica. Foram realizados cortes na metade esquerda das carcaças, no ponto P2, para a exposição do músculo Longissimus dorsi e do toucinho para a determinação da profundidade do 
músculo e da espessura de toucinho, com o auxílio de um paquímetro digital (BRIDI \& SILVA, 2007).

O percentual de carne magra na carcaça foi determinado através da equação: rendimento de carne $(\%)=60$ - (espessura de toucinho $\times$ 0,58) + profundidade do músculo x 0,10 (BRIDI \& SILVA, 2007). Os dados obtidos foram submetidos à análise de variância pelo procedimento GLM do programa estatístico SAS - Statistical Analysis System, versão 8,2 (2001), a 5\% de significância.

\section{RESULTADOS E DISCUSSÃO}

Os valores de temperatura do ar, umidade relativa do ar, temperatura de globo negro e o ITGU corresponderam a $20,65 \pm 5,28^{\circ} \mathrm{C}, \quad 75,7 \pm 12,9 \%$, $24,2 \pm 4,9^{\circ} \mathrm{C}$ e $72,4 \pm 6,3$, respectivamente. Considerando que a temperatura média registrada durante o período experimental foi inferior à crítica máxima de $27^{\circ} \mathrm{C}$ estabelecida para as categorias de crescimento e terminação (LEAL \& NÃ̃̃S, 1992) e que o ITGU calculado foi similar ao de $69,6 \pm 4,0$, obtido por
SANCHES et al. (2010) para suínos submetidos a ambiente de termoneutralidade, pode-se inferir que os animais foram mantidos em ambiente de conforto térmico durante o período experimental.

Os níveis de milheto não influenciaram ( $\mathrm{P}>0,05)$ nos parâmetros de desempenho (consumo diário de ração, ganho diário de peso e conversão alimentar) avaliados nas diferentes fases de produção (Tabela 5). Ao avaliar níveis de até $60 \%$ de milheto na fase inicial (15-30kg) (BASTOS et al., 2004) e de até $71 \%$ para as fases de crescimento e terminação (PINHEIRO et al., 2003), não foram observados efeitos da substituição do milho por milheto sobre o desempenho dos suínos. De modo similar, BASTOS et al. (2002) e MOREIRA et al. (2007), avaliando níveis de até $60 \%$ de inclusão de milheto nas dietas para suínos nas fases de crescimento e terminação, não encontraram efeitos sobre o desempenho.

De acordo com LAWRENCE et al. (1995), o milheto possui menor quantidade de energia digestível e metabolizável para os suínos em comparação com o milho, resultado de seu maior valor em fibras, o que,

Tabela 5 - Desempenho e características de carcaça de suínos alimentados com dietas contendo diferentes níveis de milheto nas fases de crescimento e terminação.

\begin{tabular}{|c|c|c|c|c|c|c|}
\hline \multirow{2}{*}{ Variáveis } & \multicolumn{4}{|c|}{-- Níveis de milheto, \% --- } & \multirow{2}{*}{$\mathrm{CV} \%$} & \multirow{2}{*}{ Valor P } \\
\hline & 0 & 25 & 50 & 75 & & \\
\hline Peso inicial, kg & 30,38 & 29,96 & 29,37 & 29,85 & 10,21 & 0,893 \\
\hline Peso final, kg & 45,59 & 46,93 & 45,80 & 45,50 & 9,62 & 0,853 \\
\hline Consumo de ração diário, kg & 1,64 & 1,76 & 1,64 & 1,66 & 11,31 & 0,456 \\
\hline Ganho de peso diário, kg & 0,76 & 0,85 & 0,80 & 0,81 & 15,18 & 0,365 \\
\hline Conversão alimentar & 2,20 & 2,08 & 2,11 & 2,21 & 14,41 & 0,697 \\
\hline Peso final, kg & 75,00 & 76,58 & 77,10 & 75,77 & 7,52 & 0,853 \\
\hline Consumo de ração diário, kg & 2,32 & 2,26 & 2,26 & 2,34 & 9,26 & 0,764 \\
\hline Ganho de peso diário, kg & 0,91 & 0,95 & 0,97 & 0,95 & 8,83 & 0,441 \\
\hline Conversão alimentar & 2,55 & 2,37 & 2,34 & 2,49 & 9,92 & 0,198 \\
\hline Peso final, kg & 99,51 & 99,88 & 101,77 & 98,04 & 8,04 & 0,807 \\
\hline Consumo de ração diário, kg & 2,71 & 2,59 & 2,60 & 2,75 & 9,45 & 0,450 \\
\hline Ganho de peso diário, kg & 0,95 & 0,96 & 0,99 & 0,94 & 9,27 & 0,651 \\
\hline Conversão alimentar & 2,87 & 2,70 & 2,63 & 2,92 & 9,28 & 0,651 \\
\hline Peso no frigorífico, kg & 93,96 & 92,53 & 95,50 & 95,20 & 6,02 & 0,797 \\
\hline Carcaça quente, kg & 79,38 & 78,08 & 79,66 & 81,41 & 6,94 & 0,775 \\
\hline Comprimento de carcaça, cm & 93,00 & 89,33 & 92,20 & 92,20 & 3,50 & 0,268 \\
\hline Espessura de toucinho, $\mathrm{cm}$ & 1,38 & 1,36 & 1,40 & 1,46 & 22,71 & 0,948 \\
\hline Profundidade de músculo, cm & 60,50 & 64,60 & 62,66 & 63,83 & 8,07 & 0,561 \\
\hline Rendimento de carcaça, \% & 84,39 & 84,36 & 83,43 & 85,54 & 2,62 & 0,449 \\
\hline Carne magra, \% & 58,02 & 58,81 & 58,14 & 57,87 & 3,21 & 0,831 \\
\hline Carne magra, kg & 45,98 & 45,86 & 46,30 & 47,12 & 6,18 & 0,871 \\
\hline
\end{tabular}

Coeficiente de variação (CV\%). 
em tese, poderia provocar aumento no consumo de ração diário dos suínos, pois estes regulam o consumo através da quantidade de energia na dieta. Todavia, essa resposta não foi observada no presente estudo, uma vez que as dietas foram isoenergéticas, sendo formuladas para energia líquida.

Todavia, existem evidências de que a suplementação de óleo nas dietas pode reduzir a velocidade do trânsito da digesta, o que possibilitaria maior tempo para a digestão e absorção dos nutrientes, melhorando a conversão alimentar (ADEOLA \& ORBAN, 1995). Essa redução da velocidade do trânsito, mediada pela colicistocnina, ocorre principalmente em resposta aos lipídios formados por cadeias entre 12 a 18 carbonos, presentes em grande quantidade em óleos e gorduras (SWENSON \& REECE, 1996). Dessa forma, dietas contendo altas concentrações de lipídios, como a dieta contendo 75\% de milheto no presente estudo, poderiam gerar melhor eficiência de utilização dos nutrientes. Todavia, essa resposta não foi verificada no presente estudo.

O peso vivo de frigorífico, peso de carcaça quente, comprimento de carcaça, espessura de toucinho, profundidade de músculo, rendimento de carcaça, percentual e quantidade de carne na carcaça não foram influenciados $(\mathrm{P}>0,05)$ pelos níveis de milheto das dietas experimentais (Tabela 5).

Os resultados obtidos no presente estudo estão de acordo com os observados por NUNES et al. (1997) e BASTOS et al. (2002), que também não obtiveram diferença para as características de carcaça de suínos a partir da inclusão de 78 e 60\% de milheto nas dietas, respectivamente. Entretanto, os pesquisadores citados ressaltaram que a adição crescente de milheto proporcionou valores mais elevados para a espessura de toucinho, porém sem diferença significativa.

\section{CONCLUSÃO}

O milheto híbrido ADR $8010^{\circledR}$ pode substituir o milho nas dietas de suínos em crescimento e terminação em até $75 \%$, sem prejudicar o desempenho e características quantitativas de carcaças dos animais.

\section{COMISSÃo DE ÉTICA}

Pesquisa aprovada pela Comissão de Ética no Uso de Animais (CEUA), sob protocolo ํㅜ 423/2012/UFMS.

\section{REFERÊNCIAS}

ADEOLA, O.; ORBAN, J.I. Chemical composition and nutrient digestibility of pearl millet (Pennisetum glaucum) fed to growing pigs. Journal of Cereal Science, v.22, p.177-184, 1995. Disponível em: <http://www.sciencedirect.com/science/article/ pii/0733521095900489>. Acesso em: 10 ago. 2012. doi: http:// dx.doi.org/10.1016/0733-5210(95)90048-9.

BASTOS, A.O. et al. Diferentes níveis de grão de milheto (Pennisetum glaucum (L.) R. Brown) na alimentação de suínos. Revista Brasileira de Zootecnia, v.31, p.1753-1760, 2002. Disponível em: <http://www.scielo.br/scielo.php?script=sci_ arttext\&pid=S1516-35982002000700018\&lng=pt\&nrm=iso $>$. Acesso em: 02 jun. 2012. doi: http://dx.doi.org/10.1590/S151635982002000700018

BASTOS, A.O. et al. Utilização do milheto (Pennisetum glaucum (l.) r. brown) grão na alimentação de suínos na fase inicial (1530kg de peso vivo). Ciência Rural, v.34, p.1915-1919, 2004. Disponível em: <http://www.scielo.br/scielo.php?script=sci_artte xt\&pid=S0103-84782004000600038>. Acesso em: 02 jun. 2012. doi: http://dx.doi.org/10.1590/S0103-84782004000600038.

BRIDI, A.M.; SILVA, C.A. Métodos de avaliação de carcaça e da carne suína. Londrina: Midiograf, 2007. 97p.

BUFFINGTON, D.E. et al. Black globe-humidity index (BGHI) as comfort equation for dairy cows. Transaction of the ASAE, v.24, p.711-714, 1981.

KIEFER, C.; QUADROS, A.R.B. Avaliação técnico-econômica da substituição do milho pela quirera de arroz em dietas de suínos. Revista Ceres, v.53, p.31-37, 2006. Disponível em: <http://www.ceres.ufv.br/ CERES/revistas/V53N305P00606.pdf>. Acesso em: 10 ago. 2012.

LAWRENCE, B.V. et al. Nutrient digestibility and growth performance of pigs fed pearl millet as replacement for corn. Journal of Animal Science, v.73, p.2026-2032, 1995. Disponível em: <http://www.journalofanimalscience.org/content/73/7/2026. full.pdf>. Acesso em: 10 ago. 2012.

LEAL, P.M.; NÃÃS I.A. Ambiência animal. In: CORTEZ, L.A.B.; MAGALHÃES, P.S.G. (Org.). Introdução à engenharia agrícola. Campinas, SP: Unicamp. 1992. p.121-135.

MARQUES, B.M.F.P.P. et al. Substituição de milho por sorgo baixo tanino em dietas para suínos: digestibilidade e metabolismo. Arquivo Brasileiro de Medicina Veterinária e Zootecnia, v.59, p.767-772, 2007. Disponível em: <http://www.scielo.br/ scielo.php?pid=s0102-09352007000300031\&script=sci_arttext $>$. Acesso em: 02 jun. 2012. doi: http://dx.doi.org/10.1590/S010209352007000300031

MOREIRA, I. et al. Diferentes tipos de milheto utilizados na alimentação de suínos em crescimento e terminação. Ciência Rural, v.37, p.495-501, 2007. Disponível em: <http://www.scielo. br/scielo.php?pid=S0103-84782007000200031\&script=sci_ arttext>. Acesso em: 10 ago. 2012. doi: http://dx.doi.org/10.1590/ S0103-84782007000200031.

MURAKAMI, A.E. et al. Avaliação econômica e desempenho de frangos de corte alimentados com diferentes níveis de milheto em substituição ao milho. Acta Scientiarum. Animal Sciences, v.31, p.31-37, 2009. Disponível em: <http://periodicos.uem.br/ojs/ index.php/ActaSciAnimSci/article/view/5761/5761>. Acesso em: 02 jun. 2012. doi: 10.4025/actascianimsci.v31i1.5761.

NUNES, R.C. et al. Utilização do grão de milheto (Pennisetum americanum L. Leeke) em rações para suínos na fase de crescimento. Anais da Escola de Agronomia e Veterinária da Universidade Federal de Goiás, v.27, p.41-47, 1997. 
PINHEIRO, M.S.M. et al. Milheto moído em substituição ao milho em rações para suínos em crescimento e terminação: digestibilidade e desempenho. Revista Brasileira de Milho e Sorgo, v.2, p.99109, 2003. Disponível em: <http://rbms.cnpms.embrapa.br/index. php/ojs/article/view/64/62>. Acesso em: 02 jun. 2012.

RAGHAVENDER, C.R.; REDDY, B.N. Human and animal disease outbreaks in India due to mycotoxins other than aflatoxins. World Mycotoxin Journal, v.2, p.23-30, 2009. Disponível em: <https:// wageningenacademic.metapress.com/content/1n4v025gr307t314/ resource-secured/?target=fulltext.pdf $>$. Acesso em: 02 jun. 2012. doi: 10.3920/WMJ2008.1066.

ROSTAGNO, H.S. et al. Tabelas brasileiras para aves e suínos: composição de alimentos e exigências nutricionais. 3.ed. Viçosa: UFV, 2011. 252p.
SALTON, J.C. et al. Cultivo de primavera: alternativa para produção de palha no Mato Grosso do Sul. Jornal do Plantio Direto, n.27, p.6-7, 1995.

SANCHES, J.F. et al. Níveis de ractopamina para suínos machos castrados em terminação e mantidos sob conforto térmico. Ciência Rural, v.40, p.403-408, 2010. Disponível em: <http:/www.scielo.br/ scielo.php?script=sci_arttext\&pid=S0103-84782010000200023>. Acesso em: 02 jun. 2012. doi: http://dx.doi.org/10.1590/S010384782009005000257.

SAS Institute. SAS user's Guide statistics. Statistical Analyses System Institute, Versão 8.02. Cary, NC, 2001. 1471p.

SWENSON, M.J.; REECE, W.O. Dukes - Fisiologia dos animais domésticos. 11.ed. Rio de Janeiro: Guanabara, 1996. 856p. 